\title{
On the problem of relevance to develop emotionally competent behavior in children with intellectual disabilities
}

\author{
Natalia Verkhoturova ${ }^{1,2, *}$, Alexey Dmitriev ${ }^{2}$, Svetlana Dmitrieva ${ }^{2}$ \\ ${ }^{1}$ Krasnoyarsk State Pedagogical University named after V.P. Astafyev, 89, Ada Lebedeva Str., \\ 660049, Krasnoyarsk, Russia \\ ${ }^{2}$ Moscow Region State University, 10A, Radio str, 105005, Moscow, Russia
}

\begin{abstract}
Nowadays, improvement of the education quality remains a burning issue in the world and, in particular, in Russia. Modern social, economic and cultural transformations have bred new values in education to appear; educational objectives, goals, content and results have been reviewed. Contemporary changes have generated a reasonable request of the society for training a comprehensively developed, cultured and competent person who is given the necessary set of social important competences for various culture-congruent activities; actively interact with society and efficiently adopt social roles. Current trends dictate to look for new approaches and methods in education that actively form personal and social skills and competencies to facilitate a better social adaptation and socialization of every person with understanding of their potential. In this regard, investigation of emotional competence of school students with intellectual disabilities is of special relevance; state and condition of the disorder in many ways define the capacity of sound socialization for this group of children. Goal of our research is to analyze theoretical background, studies and methodological concepts in world and Russian psychology on the problem of regulation of emotional response of school students with intellectual disabilities through shaping emotional competence in their behavior; to pinpoint problems and potential to scrutinize this topic. The scope of the research is the process of emotion regulation of school students with intellectual disabilities through shaping emotional competence, which encompasses abilities to monitor, control and manage their emotional response in social environment. The research found that most scientists although declare the need for special programs to study and correct the emotional responses of intellectually disabled students with a view to their best socialization in modern society, there are still deficits in both the science and the practice of special psychology related to the development and implementation of technologies for monitoring, predicting and managing emotional responses among this group of schoolchildren.
\end{abstract}

\footnotetext{
*Corresponding author: 7828262@inbox.ru
} 


\section{Introduction}

Challenge of managing the quality of education under competency-based paradigm is reflected in a range of recent studies (V.A. Bolotov, V.V. Serikov [1], A.A. Dmitriev [2], A.V. Khutorskaya [3], E. M. Korotkov [4], M. M. Potashnik [5], J. Raven [6], T. A. Strokova [7], V. I. Zagvyazinsky [8], I. A. Zimnyaya [9] and others). Russian researchers pinpoint that the new paradigm of education shifts the emphasis from principle of adaptability to principle of competence of graduates of educational institutions. At same time, the content does not boil down to knowledge-based component, but it offers students a combination of key functions, social roles, general social experience to tackle problems in life, the development of which ensures consistency in socio-cultural progress.

In the work of V.A. Bolotov, V.V. Serikov [1], competence is considered as a complex synthesis of cognitive, subject-matter-practical and personal experience of students, contributing to self-realization, finding students their place in the world. A.A. Dmitriev formulates the following definition, developing the issues of defining the patterns of social and personal competences and their structuring: «Competence is a way of activity, allowing to use knowledge and skills in various situations; competence is compound phenomenon that is made up of skill set» [2]. Acquirement of structural and functional characteristics of a given competence indicates a certain level of literacy of learners in the relevant area.

An analytical review of contemporary approaches to understanding the essence and determinative dependency of the emergence and presentation of competence as a certain level of functional literacy points to the sociocultural phenomenological basis of the concept. Arguing for this point of view, I.A. Zimnyaya [9] notes that all competences by their origin are social, since they are developed and shaped in society; they are also social in their content, because they manifest themselves and function in this society. Consequently, their formation is socially significant and necessitates the search for new approaches and technologies to target them in the younger generation with a view to the best socialization in modern society.

M.M. Potashnik held to a similar opinion [5]. He highlighted the need to change the vector of modern education from traditional knowledge-oriented to cultural competencybased approach, inspired with a world view and strengthening the upbringing function of education. According to the author, the orientation of the modern model of education should be towards the formation of socially significant results in the younger generation, which are dictated by life conditions. Such a reinterpretation resulted in «righteous and long-awaited equalization of socially significant assessments of its quality; elimination of the deep seated contradiction between children prone to intellectual activity and children with impaired intellectual development which will undoubtedly lead to an increase of quality of life» [5]. This approach offers a real opportunity to appreciate not only the performance of lyceums and gymnasiums, but also of general education schools where children with special needs are taught well.

V.P. Panasyuk describes in his doctoral thesis the qualitative parameters of the educational process that stands for a range of features. These features sustain the implementation of social tasks on shaping and developing the personality in terms of educatedness, behavior as well as formed social, psychological and physical qualities. Quality improvement of education process is seen in tackling the contradictions between the modern requirements for the level of education in schools, which aims at comprehensive development of graduates, and narrow possibilities to work with these objectives, applying traditional methods for the quality control.

A similar criticism of the views of the traditional education system, focused on a narrowly focused knowledge component, we find in the statements of E.A. Yamburg, who 
rightly admits that: "... without essentially new content of humanistic education based on new values, it makes no sense to talk about the quality of school education" [10,11].

With the new definition of quality, the competency-based approach is understood as the orientation of education towards the comprehensive development of the learner's personality as a result of the formation of such personal qualities as competence by means of solving social practice-oriented tasks in the educational process. In this understanding, the content of education is a generalized multivariate and multi-vector social experience, pedagogically adapted for development by students with both normal and impaired development. It is focused on the active appropriation of personal and socially significant skills, abilities and relationships that promote personal and professional self-realization of each person, taking into account their potential.

\section{Scientific grounds}

By dwelling on ideas of competency-based paradigm of education, it can be stated that the quality of modern education should be determined not only with the volume and level of knowledge and skills in the functioning of cognitive structures (which is now applied in many schools), but also the level of personal spiritual, moral and emotional development of younger generations. Thus, solution to the key challenges of improving the quality of general and special education can only be addressed if a comprehensive set of integrative (encompassing all aspects of mental development), socially significant competences is taken. They should consider maximum probable results (educatedness, manners and outlook) with a certain accuracy. Without a doubt, great attention must be paid to the comprehensive shaping of a child's psyche, including emotional and personal barriers in the overall mental growth.

The words of L. S. Vygotasky are clearly relevant to us today: "For some reason, our society has developed a one-sided view on human personality and understands its genius and talent only in relation to intelligence... The emotional side of the personality has no less meaning than other parties and forms the subject to care and nurture in the same way as the mind and will» [12]. Defining the leading role of a cultural factor for children with both normal and impaired intelligence development, the classical of Russian psychology and pedagogy pointed to the need to create social situations in education of children, comparing it to the condition and cause general mental and, in particular, emotional formation in childhood.

S. L. Rubinstein pointed out the importance of providing children with targeted training in emotional regulation of behavior: «The development of emotions is inextricably linked to the development of the personality as a whole... emotions do not develop on their own... therefore, the main task is to guide and regulate them properly through the activities in which they manifest and form» [13]. The methodological views of the scientist show the need to consider emotions as the ultimate mental function, the training and improvement of social characteristics (abilities) of which takes place only in the socially meaningful activities and environment ripe for social experience that facilitates and encourages their subsequent development.

The works of A.A. Dmitriev, N.Y. Verkhoturova [14], P.L. Harris [15], E.P. Ilyina [16], P. LaFreniere [17], L.A. Sroufe [18] also highlight that children should be specially trained to manage their emotions and control their expression. The development of these skills is vital since they allow a child to successfully navigate the environment; to adequately perceive and reflect the information in a meaningful way, by coordinating the emotional response to the context of the situation; to master the norms and means of cultural behavior and congruent interaction with others; to respect the use of personal resources; to maintain 
stability and emotional balance in different situations and under emotional strains; to take an active part in the development of various forms of social life and social activity.

Studies by Russian and foreign psychologists A.A. Dmitriyev, N.Y. Verkhotourova [14], P.L. Harris [15], P. LaFreniere [17], L.A.Sroufe [18], L.S. Vygotsky [19], A.V. Zaporozhets, Y.Z. Neverovich [20], A.D. Kosheleva, V.I. Pereguda, O.A. Shahrayeva [21], V.V. Lebedinsky [22], etc.) showed that emotions play an important role in a person's mental and somatic health, aiding to perceive reality, respond adequately, evaluate, regulate and manage one's own behavior. The state of emotional response has a significant impact on the entire mental activity of a child: their cognitive processes, motivation, behavior, personality structures; develops orientation, interests, self-esteem; determines the success of the subject in all types of activity; expands the scope of interpersonal and social contacts.

In the works of A.V. Zaporozhets, Y.Z. Neverovich [20], A.D. Koshelova, V.I. Pereguda, O.A. Shagraeva [21], the formation of social emotions in childhood as a powerful regulator of behavior is considered and their role in the design not only of personal, but also of cognitive processes. The authors point to the progression of emotional response in ontogenesis, from elementary forms of emotional reflection to higher socially determined, consciously regulated and managed forms of emotional behavior. The formation of social emotions is seen as a hierarchical process that is gradually revealed as the child develops physically and mentally. According to modern researchers, (A.A. Dmitriev, N.Y. Verkhoturov [14], P.L. Harris [15], L.A. Sroufe [18]), these progressive changes include emotional complexity and susceptibility to emotional expression of others, increased understanding of the meaning of their emotions, emotional reactions of other people, rules of expression and containment of emotions in situations of social interaction. At the same time, scientists note the advancement of mechanisms of regulation, monitor and control in emotional response during the childhood years, as the major marker for maturity of emotional reactions.

These progressive changes in the development of higher forms of emotional response can be considered as a sequential «increase» of emotional experience, revealed in the emotional literacy of a person, their knowledge, skills, ability to adequately understand emotional reactions of others, constructively express their own emotions, productively interact emotionally on the basis of external expressive means of emotional response, implement emotional regulation, control their behavior in situations of social interaction while preserving their emotional well-being and health.

The integrative representation of abilities that ensure the emotional competence of a person today are among the socially significant personal traits demanded by modern society, as they ensure that the subject is successful in key life functions as activities, relationships, fulfilling social roles. Thus, experts should scrutinize "emotions" in timely manner with purposefully organized support, evaluation of maturity and special technologies.

The progressive development of emotional literacy in childhood is gradual. It is consistent with the laws of general mental development and requires professional guidance, at least as much as support for cognitive processes. Despite the practical importance expressed in addressing these issues, the practice of general and special education shows that the attention of specialists is primarily focused on the development of the cognitive skills and abilities of children. This is achieved through defining the predominance of cognitive literacy and giving it priority in preparing individuals for effective social functioning in society, thereby abandoning the purposeful formation of emotional competence of children.

In the context of a competency-based paradigm of modern education, aimed at the development of a culturally competent person with the set of socially relevant personal competences, of particular importance is the development of technologies for managing the 
emotional response of schoolchildren, with both normal and impaired intellectual development and the formation of their emotionally adequate behavior. In the light of the current trends in science and the practice of general and special education, this area of research is in great demand. It has a high theoretical and practical value and constitutes one of the priority areas of research in modern science.

\section{Discussion}

There is no doubt that the possibilities of social adaptation of schoolchildren, both those with normal development and those with intellectual disabilities, will be determined to a large extent by the peculiarities of the emotional regulation of their behavior, as well as the level of their complex competences in managing their emotional responses in situations of social interaction with adults and peers. The data available in special psychology show that in the life of intellectually impaired students, emotional response, as in normal development, plays an important role as an integral component of overall mental development, the state of which determines to a large extent the shape of other aspects of mental maturity.

Analysis of the results of modern researches (V.V. Lebedinsky [22], V.G. Petrova, I.V. Belyakova [23], I.A. Korobenikov [24], V.I. Lubovsky [25], S.Y. Rubinstein [26], O.E. Shapovalov [27], L.V. Zankov [28], A. Dmitriyeva, N.Y. Veroturova [29], etc.) showed that the problems of socialization encountered by students with intellectual disabilites are not only mediated by the arrested development and an intellectual defect. First of all, the difficulties in socialization stem from the lack of emotional competence, that is revealed in a generalized set of abilities to manage emotional response in different situations of social interaction.

Attention to the possibility to develop emotional aspect of intellectually impaired students and to form advanced emotionally competent behavior by creating a special social environment is called in the work of S.Y. Rubinstein [26]. The author notes that the personality of a mentally retarded schoolchild, as well as that of his peer with normal development, is shaped by the social relations and social environment in which the child grows. Criticizing one of the approaches of that time, which asserted the tendency of the mentally retarded towards antisocial behavior to be innate, she pointed out: «It is not the disease that causes the antisocial, immoral actions of mentally impaired children, but the environment in which the child lives and develops. ...Higher feelings not only can, but must be nurtured in children with arrested development» [26]. The upbringing of higher feelings and the target training of appropriate social behavior do not only make it possible to overcome the difficulties of biological nature and to increase the effectiveness of the special educational process, but it also opens up possibilities to develop the personal potential of a group of schoolchildren, their awareness of their importance in carrying out various social activities; and facilitates their successful socialization in the following years.

A similar point of view was made by L.V. Zankov [28], who noted that, emotional manifestations of students with an intellectual disabilities became more conscious and regulated with age. This demonstrates, in the opinion of the scholar, the importance of timely development of their emotional and personal traits of correct behavior in everyday life, which contributes to the social adaptation of this group of schoolchildren.

Resources for the development of the emotional sphere of students with arrested development in comparison with cognitive processes, as well as the priority to form their emotional traits and socially approved behavior, which aid children to adapt, are mentioned in the work by V.G. Petrova, I.V. Belyakova [23]. Petrova, I.V. Belyakova [23]. The authors stress that in order to help students with intellectual disabilities adapt to the environment, an important factor is the special training for the formation of positive 
emotional and personal traits. In turn, the tendency of this group of students to be emotionally confused is due to their lack of developed practical skills of personal and emotional preparedness.

The important role of special training in overcoming the difficulties of mental and emotional-volitional development was pointed out by V.I. Lubovsky [25]. According to the scientist, it is possible to successfully adapt a child in school by overcoming the difficulties of mental development, only by organizing such education, which will be one of the conditions for their adaptation in later adult life. The views of V.I. Lubovsky [25] emphasize the need for schoolchildren to develop socially significant practical skills and abilities that would enable them to accumulate personal experience throughout their life, to develop social practices, life and professional skills.

The crucial role of the social factor in the mental and, in particular, emotional development of a child with intellectual disabilities has been noted in the studies of many Russian psychologists: V.G Petrova, I.V. Belyakova [23], S.Y Rubinstein [26], O.E. Shapovalova [27], A.A. Dmitriev, N.Y. Verkhoturova [29, 30, 31], M.G. Agavelyan [32], E.V. Semenova [33] and others. In experimental studies, the authors have described the features of the emotional sphere of students with intellectual disabilities and have shown that positive changes in their development are possible, provided that the educational process is adequately organized. The specific defiant and compensatory features of this nosological group of children should be taken into account.

There are far fewer works addressed to the problem of empirical study of individual emotional reactions of students with impaired intellectual development, their theoretical understanding in the context of analysis of internal mental regulation and control of their behavior and activities. The thesis researches of O.E. Shapovalova [27], N.Y. Shapovalova [27], N.Y. Verkhoturova [30] justify the need to organize optimal conditions using special methods and means based on the capacities of the given schoolchildren. The effect of their psychocorrective programs and technologies on the positive dynamics in the development of the emotional component of the students' personalities is also proved empirically.

On the basis of the above, it is apparent that purposeful formation of emotionally competent behavior of students with intellectual disabilities, which shows itself in ability to control and manage their social behavior and activity, is not only feasible, but is badly needed in order to facilitate best adaptation of the children to their schoolmates, improve processes of social interaction with adults and peers and their future socialization.

\section{Results of the research}

Based on the analysis of existing scientific approaches that consider competence as a complex cultural-didactic holistic structure, a synthesis of cognitive, personal and subjectmatter experience, and current educational practices, it may be argued that the ability of schoolchildren with and without intellectual disabilities to adapt socially will be determined to a large extent by the ability to regulate their behavior emotionally, as well as their level of emotional competence, revealed in a generalized set of abilities to manage the emotional response of schoolchildren in different situations of social interaction.

By emotional competence, we mean the composite integral personality trait, which is the sum of key competences (multi-functional package of knowledge, skills, abilities and relationships) which are the total of the functional activity of a multi-component complex (synthesizing communicative, interactive, perceptual, cognitive and regulatory components). The latter shows itself in the capacity for adequate management of emotional responses in situations of social interaction, as well as formed through a purposeful organization, operationally predicted in the area of potential development of the student and with the possible degree of precision, results of education. 
The formation of emotional competence includes a significant set of emotional competences, integrating knowledge, skills, emotional qualities and traits of the subject, its orientation, affiliate needs, values and interests. All of them become the object of the practical activities of social, thematic and personal focus. Emotional competences ensure adaption to key social functions and roles that help children become a part of the society.

Despite the unanimity of views of Russian and foreign authors on the need to change the orientation and content of the modern education system, to rethink its objectives and results from the perspective of a competent educational paradigm, the questions on differentiation of competences and their classification grounds remain controversial; determination of the orientation of different groups of competences to the rank of «basic», «key», «educational», «professional»; identifying hierarchical links and levels of priority and social significance.

An insight into the problem of competence demonstrates the existence of a large number of well-argued views on the issues of systematization of key social competences, their unification and grouping on various grounds, elaboration of a common nomenclature of social competence and unifying criteria for their component indexing. Having studied the texts of the basic documents «Concepts of Modernization of Russian Education for 20162020», "Strategies of Modernization of General Education Content», Federal State Educational Standards of Primary and General Education, we did not find independently allocated emotional competence in the nomenclature of «key social competences» adopted to date. In addition, we have found that in the texts of the same documents, as well as in the generalized systematics accumulated by modern science, some meaningful aspects of emotional literacy are represented through a qualitative and functional description of other social competencies. These include: value-focused competences, self-improvement and self-regulation, cognitive competence, competence for integration, health, competence for social interaction, communication and other more private competencies.

The absence of emotional competence as independent standard of «key social competences», in our opinion, in many ways will prevent successful preparation of harmoniously developed and culturally competent person possessing the necessary set of socially significant abilities to ensure his or her convenient integration in the society. Current clash of views clearly works the ambiguity of scientific approaches, both in the understanding of the phenomenon of emotional competence and its component structure as well as implementation of complex empirical studies, which aim to assess its progressive development in childhood and to determine the standards for the appearance of neogenesis and the dynamics of their formulation in the context for normal and arrested intellectual development.

An analysis of the theoretical assumptions, teachings and methodological grounds on the problem, as well as the relevant research, shows that most scientists declare the need to understand emotional competence as complex, multi-component phenomenon characterized by its multi-dimensionality and polyfunctionality. However, as a result of the analytical review, we have identified the lack of comprehensive integrative studies of emotional competence, which are based on a component-indexed system for measuring gradual development, accumulating and formalizing all the components of its structural organization.

The literature review and the conducted research show that there are no complex integrative programs and technologies that could form emotional and competent behavior of schoolchildren with intellectual disabilities by means of purposeful development of their emotional literacy, which encompasses the skills of regulation, control and management of their emotional behavior in the social environment.

Before creating such technologies, a theoretical and methodological concept should be elaborated to comprehensively follow emotional responses of children with intellectual 
disabilities. There will be measured technological parameters, values and methodological means for consequential study, monitoring and conclusions on further progression. It will also include development of technological models for the quality control of formation of emotionally competent behavior of the children.

\section{Conclusions}

The analytical review of contemporary Russian and foreign literature showed, on the one hand, the multilateral interest of researchers in studying the emotional sphere of schoolchildren with intellectual disabilities, the existence of programs and technologies for improving it, and, on the other hand, the lack of comprehensive researches aimed at developing concepts and psychocorrectional technologies to manage the emotional response of schoolchildren with intellectual disabilities through the formation of emotionally competent behavior. The implementation of this research is extremely important, under the conditions of a modern competency based paradigm of education, which is aimed at developing a culturally competent person with the necessary set of socially significant personal competencies. It is driven by theoretical and practical relevance.

Current approaches of special education indicate that in the context of schooling, due attention is not paid to the processes of accompanying the emotional response of students with arrested development; lack of timely monitoring of the state of mental maturity in their emotional processes; a comprehensive assessment of the correspondence of qualitative changes in the emotional sphere of students to their age and general mental development has not been introduced into the duties of a psychologist.

Psychological guidance can be carried out by means of developing special technologies aimed both at the timely assessment and monitoring of the development of emotional qualities; evaluation of their level of formation and compliance with the periodical dynamics of childhood; technologies of targeted age-focused formation of emotionally competent behavior in students with intellectual disabilities.

We believe that the formation of emotionally competent behavior of students with intellectual disabilities through the targeted development of emotional literacy, which is expressed in the ability to regulate, control and manage their emotional behavior in a social environment, will have a positive impact on overall mental development and the establishment of social interactions for these children; it will improve their academic performance and quality of their life in the future: shaping emotional competence will facilitate socialization of children with arrested development.

\section{References}

1. V.A. Bolotov, V.V. Serikov, Pedagogy 10, 8 (2003)

2. A.A. Dmitriev, Special education: scientific and methodical journal 3, 12 (2014)

3. A.V. Khutorskoy, Public education 2, 58 (2003)

4. E.M. Korotkov, Quality management of education: a textbook for universities (Moscow, Akademicheskij proekt Publ., 2007)

5. M.M. Potashnik, The quality of education: problems and management technology (Questions and Answers) (Moscow, Pedagogicheskoe obshchestvo Rossii, 2002)

6. Dzh. Raven, Competence in modern society: influence, development, implementation (Moscow, Kogito-Centr Publ., 2002)

7. T.A. Strokova, Pedagogical innovations at the present stage of development of 
education (Tyumen', TGU Publ., 2010)

8. V.I. Zagvyazinskij, Ways to implement and evaluate the quality of education: problems, research, practical experience and prospects: materials of the All-Russian Scientific and Practical Conference (Tyumen', TGU Publ., 2014)

9. I.A. Zimnyaya, Key competencies as an effective and targeted basis of the competencybased approach in education. Russia in the Bologna Process: proceedings of a methodological seminar (Moscow, GTU Publ., 2008)

10. V.P. Panasyuk, The pedagogical system of intraschool quality management of the educational process: abstract of the dissertation for the degree of Doctor of Pedagogical Sciences (St. Petersburg, SPGPU, 1998)

11. M.M. Potashnik, E.A. YAmburg, D.S. Matros, Management in education. Education Quality Management: Practice-oriented monograph and methodological allowance (Moscow, Pedagogicheskoe obshchestvo Rossii, 2000)

12. L.S. Vygotsky, Pedagogical psychology (Moscow, Pedagogika-Press Publ., 1999)

13. S.L. Rubinshtein, Fundamentals of General Psychology (St. Petersburg, Piter Publ., 1999)

14. A.A. Dmitriev, N.Yu. Verhoturova, Siberian Pedagogical Journal 3, 90 (2018)

15. P.L. Harris, The Development of Psychological understanding (Oxford, England, Basil Blackwell, 1989)

16. E.P. Ilyin, Emotions and feelings (St. Petersburg, Peter Publ., 2001)

17. P. Lafrene, Emotional development of children and adolescents (St. Petersburg, praimEVROZNAK, 2004)

18. L.A. Sroufe, Emotional Development: The Organization of Emotional Life in Early Years (Cambridge, England, Cambridge University Press, 1996)

19. L.S. Vygotsky, Doctrine of emotions (Moscow, Pedagogika Publ., 1984)

20. A.V. Zaporozhets, Ia.Z. Neverovich, A.D. Kosheleva, Emotional development of a preschooler (Moscow, Prosveshchenie Publ., 1985)

21. A.D. Kosheleva, V.I. Pereguda, O.A. Shagraeva, Emotional development of preschool children (Moscow, Akademy Publ., 2003)

22. V.V. Lebedinsky, Mental development disorders in childhood (Moscow, Akademy Publ., 2003)

23. V.G. Petrova, I.V. Beliakova, Psychology of mentally retarded schoolchildren (Moscow, Akademy Publ., 2002)

24. I.A. Korobejnikov, Developmental Disabilities and Social Adaptation (Moscow, PER SE, 2000)

25. V.I. Lubovsky, T.V. Rozanova, L.I. Solnceva, Special psychology: textbook (Moscow, Akademy Publ., 2005)

26. S.Ya. Rubinstein, The psychology of the mentally retarded pupil (Moscow, Prosveshchenie Publ., 1986)

27. O.E. SHapovalova, Features of the emotional development of mentally retarded schoolchildren (Moscow, MPGU, 2005)

28. L.V. Zankov, Psychology of a mentally retarded child (Moscow, State educational and pedagogical publishing house of the people's Commissariat of the RSFSR, 1939)

29. A.A. Dmitriev, N.Yu. Verkhoturova, RUDN Journal of Psychology and Pedagodics 1, $124(2013)$ 
30. N.Yu. Verhoturova, Psychocorrectional technology for managing the emotional response of students of primary school age with impaired intellectual development. (Abstract of dissertation for the degree of candidate of psychology) (Ekaterinburg, Ural State Pedagogical University Publ., 2010)

31. N.Yu. Verkhoturova, V.V. Abdulkin, SGEM International Multidisciplinary Scientific Conference on Social sciences and Arts 1(1), 623 (2016)

32. M.G. Agavelyan, R.O. Agavelyan, All-Russian scientific-practical conference "The humanization of education - the imperative of the XXI century". Perm' (1997)

33. E.V. Semyonova, Bulletin of Cherepovets State University: Scientific Journal 3, 108 (2008) 